\title{
Social networks and renewable energy technology adoption: Empirical evidence from biogas adoption in China
}

He, Pan ; Lovo, Stefania; Veronesi, Marcella

Publication date:

2021

Document Version

Publisher's PDF, also known as Version of record

Link back to DTU Orbit

Citation (APA):

He, P., Lovo, S., \& Veronesi, M. (2021). Social networks and renewable energy technology adoption: Empirical evidence from biogas adoption in China.

\section{General rights}

Copyright and moral rights for the publications made accessible in the public portal are retained by the authors and/or other copyright owners and it is a condition of accessing publications that users recognise and abide by the legal requirements associated with these rights.

- Users may download and print one copy of any publication from the public portal for the purpose of private study or research.

- You may not further distribute the material or use it for any profit-making activity or commercial gain

- You may freely distribute the URL identifying the publication in the public portal

If you believe that this document breaches copyright please contact us providing details, and we will remove access to the work immediately and investigate your claim. 


\section{Social Networks and Renewable Energy Technology Adoption: Empirical Evidence from Biogas Adoption in China}

by Pan He, Stefania Lovo

and Marcella Veronesi

Discussion Paper No. 2021-19

Department of Economics

University of Reading

Whiteknights

Reading

RG6 6AA

United Kingdom

www.reading.ac.uk 


\title{
Social networks and renewable energy technology adoption:
}

\section{Empirical evidence from biogas adoption in China}

\author{
Pan $\mathrm{He}^{\mathrm{a}}$ \\ Stefania Lovo ${ }^{b}$ \\ Marcella Veronesi ${ }^{\mathrm{c}}$
}

\begin{abstract}
We provide novel empirical evidence on the association between social networks and the adoption of renewable energy technology. We distinguish between two main transmission mechanisms through which social networks can affect renewable energy technology adoption: information diffusion and social influence. Using data primarily collected from rural China on biogas adoption, we find that both mechanisms are at work. In addition, we find that information spreads through trusted network members, such as friends and family, while social influence is mainly exercised by government officials. Government officials are more likely to promote the adoption of technology by leading by example rather than by spreading information.
\end{abstract}

Keywords: Social networks, social influence, information diffusion, renewable energy, biogas, China.

JEL Codes: O13, O33, Q16, Q42, Q55, Q56

\footnotetext{
a The West Center for Economics Research, Southwestern University of Finance and Economics, Chengdu 611130, China. Email: hepan@swufe.edu.cn.

${ }^{\mathrm{b}}$ Department of Economics, University of Reading, Email: s.lovo@ reading.ac.uk

c, Department of Technology, Management and Economics, Technical University of Denmark, and Department of Economics, University of Verona, Italy. Email: marcella.veronesi@univr.it
} 


\section{Introduction}

Decentralization of government interventions to the local level has become a prominent feature of development initiatives, including the promotion and adoption of renewable energy. Understanding how information and behavior spread at the local level and ultimately impact the adoption of renewable energy is key for the effective design of technology promotion policies. This paper provides novel empirical evidence on the association between social networks and the adoption of renewable energy technology. In particular, this study distinguishes between two main transmission mechanisms through which social networks can affect renewable energy technology adoption: information diffusion (also known as social learning) and social influence (also known as endorsement effect or social pressure). ${ }^{1}$

Information about new technology, such as its existence and benefits, and how it is used, may be spread through social networks. Obtaining information makes individuals aware of, or more knowledgeable about, a technology, and reduces learning costs, which affects adoption (Conley and Udry, 2001; Jackson and Yariv, 2005; Conley and Udry, 2010). ${ }^{2}$ In this case, the quality of information is crucial, as is who delivers it (Hogset and Barrett, 2010). On the other hand, individuals may be affected by the choices of others in their social network. Bursztyn et al. (2014), for example, show that people imitate others' adoption for several overlapping reasons, including aligning with norms or interpreting adoption as an indicator of quality. Recent studies show that social norms can affect the adoption of renewable energy technologies such as residential solar photovoltaic panels, in particular, through social influence (e.g., Bollinger and Gillingham, 2012; Graziano and Gillingham, 2015; Rode and Weber, 2016, and Baranzini et al., 2017). Social influence can be sufficient to trigger adoption through aggregate information about others' behavior (Hogset and Barrett, 2010).

Empirical studies have often conflated information diffusion and social influence, and only recently few attempts have been made to empirically disentangle them in the context of microfinance and agricultural technology adoption in developing countries (e.g., Banerjee et al., 2013; Cai et al., 2015; Maertens, 2017). ${ }^{3}$ To the best of our knowledge, no studies have distinguished between information diffusion and social influence as two main transmission mechanisms through which social networks can affect renewable energy technology adoption. Hence, we aim to contribute to the literature by separating the role played by information diffusion and social influence on renewable technology adoption using observational data.

\footnotetext{
${ }^{1}$ See for instance, studies by Rogers (1995), Conley and Udry (2001), Jackson and Yariv (2005 and 2007), Kremer and Miguel (2007), and Jackson (2008). Social influence can be seen as a way to avoid conflict by harmonizing with the prevailing behavior in the network (Hogset and Barret, 2010).

${ }^{2}$ In most cases, better knowledge increases the likelihood of adoption. However, as shown in Kremer and Miguel (2007), it may have a negative effect if individuals overestimate the benefits of the technology at the beginning and then figure out the real benefits after obtaining information through their social networks.

${ }^{3}$ The technologies studied in the existing literature include for instance high-yielding seed varieties (Foster and Rosenzweig, 1995, and Munshi, 2004); sunflowers (Bandiera and Rasul, 2006); fertilizers and pineapples (Conley and Udry, 2001, 2010); genetically engineered cotton (Maertens, 2017), and soil management practices (Beaman et al., 2018).
} 
In our study, we focus on the adoption of biogas technology in rural China. As in the case of most renewable energy technologies, the direct financial and health benefits to households are associated with broad social and environmental benefits, e.g., in the form of reduced greenhouse gas emissions. Given these social benefits, the central Chinese government launched a subsidized biogas program in 2003 to encourage the adoption of biogas in rural areas. The adoption rate of biogas among eligible households, however, remains low (MOA, 2014), and it is, therefore, important to study the factors that promote their adoption.

In addition, an essential feature of biogas technology is that it is highly visible. Biogas requires a biogas pool of $6-8 \mathrm{~m}^{3}$ for the methane fermentation process from organic waste. Its installation requires some major remodeling of the house since the toilet, pigsty and kitchen have to be connected to the pool (CRESP, 2008; Weiland, 2010). The construction process usually takes several weeks. Visibility is a key mechanism through which social influence operates, as explored below. This aspect has an important influence on how social networks operate and allows us to disentangle the role played by information diffusion from the role played by social influence on the adoption of the technology.

For this study, we specifically collected data on farmers' adoption of biogas and the composition of their social network. Our network data have several advantages. First, the network is technology-specific and explicitly refers to information exchange between the respondent and people in the network. Hence, as opposed to information networks based on adopters only, our network also includes non-adopters, and so captures the full extent of information diffusion by focusing on information rather than adoption. Indeed, Banerjee et al. (2013) show that information transmitted by non-adopters also plays an important role. Second, our network data provide additional information on the characteristics of network members, such as their relationship and whether they are considered trustworthy. Third, as opposed to networks measured based on local residents only (i.e., other villagers), our data allow for network members to live outside a respondent's local area. Last but not least, when compared to network measures based on random matching within the sample, where each respondent is matched to a number of other random respondents, our network data are more likely to include both key network nodes and weaker ties, i.e., socially distant people with whom one has infrequent contacts but carry relevant information (Granovetter, 1973).

Our results show that both information diffusion and social influence are at work, yet their effects are not unconditional. In particular, we find a stronger correlation between biogas adoption and information diffusion through trusted people such as friends and family, while social influence is mainly exercised by government officials. This indicates government officials are more likely to promote the adoption of technology by leading by example rather than by spreading information.

As for other studies that use observational data for network analysis, our results are subject to concerns about potential homophily and correlated effects. This implies that the nature of our study is correlational, and we cannot claim causal results. Nevertheless, our findings are robust to a broad set of robustness checks that mitigate these concerns. In our empirical model, we 
control for a rich set of covariates, including personality traits and risk preferences, and village fixed effects to account for potential omitted variables. In addition, we provide a set of alternative specifications, including a falsification test and a placebo test, which confirm the robustness of our results.

This paper proceeds as follows. Section 2 provides background information. Section 3 presents a conceptual framework that lays out how social networks can affect renewable technology adoption. Section 4 describes the data and Section 5 the empirical approach. Section 6 presents the results and shows that they are robust to several sensitivity checks, alternative specifications, including a falsification test and a placebo test, and when we account for the small number of clusters. Section 7 concludes.

\section{Background}

In rural China, biogas used in a small household is usually produced in a fixed dome digester, often built underground and with a capacity volume of 6-8 $\mathrm{m}^{3}$. The biogas digester is combined with the pigsty and toilet so that organic waster can be fed to the digester and be degraded by bacteria in anaerobic digestion (Rajendran et al., 2012). Building biogas digester brings several benefits to rural households (Katuwal and Bohara, 2009; Zheng et al., 2010; Panwar et al., 2011). First, using biogas to substitute fossil fuels saves time and costs related to traditional energy materials. Second, collecting organic waster eliminates the spread of disease. Third, organic fertilizers obtained as by-products can reduce the use of chemical fertilizers. In addition, biogas can bring socio-economic benefits by protecting forest lands and contributing to the reduction of $\mathrm{CO}_{2}$ emissions and air pollution that significantly exceed possible negative externalities such as odor emissions. Indeed, Krekel et al. (2020) find that, even in the presence of large biogas plants, negative externalities are very limited.

It costs approximately 3000 Chinese Yuan (¥) to build a biogas pool. ${ }^{4}$ In addition to this initial investment, adopters need to learn how to use the biogas and maintain the pool. A lack of money and knowledge of the technology can discourage the adoption of biogas. Hence, to encourage the adoption of biogas in rural areas, the Chinese central government launched a subsidized biogas program in 2003. Government officials advertised the biogas subsidy program in each village at the villagers' meeting. In a village, government officials are usually local residents, and their house is located in the village. Government officials themselves residents of a village were also eligible to apply to the program. If households wanted to participate in the biogas program, they needed to submit an application to the government officials for their village. The application was then sent to county government officials, who decided whether to approve it based on the program budget. Participants received subsidies to build a biogas pool and alter the toilet, the pigsty, and the kitchen. In the north-western and north-eastern areas, the amount of subsidies was $¥ 1200$, in the south-western area the amount was $¥ 1000$, and in other areas the amount was $¥ 800$. The subsidy was economically attractive

\footnotetext{
${ }^{4}$ One U.S. Dollar $\approx$ Six Chinese Yuan (¥).
} 
to adopt the biogas technology due to an estimated annual benefit of $¥ 4500$ (MOA, 2007). Yet, the adoption rate of biogas technology among eligible households is still low, involving about one-third of the total rural population (National Development and Reform Commission, 2017).

\section{Conceptual framework: Social networks and technology adoption}

A social network is defined as a set of actors and connections (called "ties") between pairs of actors (Wasserman and Faust, 1994). Actors may be people, organizations, countries, or any units of interest. The members of a network connected to the actors are defined as "alters." The role of social networks as a driver of technology adoption, among other outcomes, has been studied in the literature (see Foster and Rosenzweig, 2010 for a review), and the effects are often decomposed into two main mechanisms: information diffusion and social influence. ${ }^{5}$ The first mechanism refers to the diffusion of information about technology within a network which increases awareness and/or reduces learning costs and the uncertainty surrounding its adoption. According to Hogset and Barrett (2010), this effect is more likely to occur when an actor actively seeks information and constructs beliefs from network members with a particular status and/or precise information.

The second mechanism is social influence, which refers to the desire to harmonize with others with the aim of imitating and/or avoiding conflict and/or signaling endorsement. Social influence, for instance, can relate to the establishment of social norms with which people conform or comply to avoid clashes with other members of the communities or as a form of obedience (Hogset and Barrett, 2010). It can also be associated with an endorsement effect where the action of adoption carries an additional connotation, for example, signaling approval or support for a shared objective. For this mechanism, aggregate information about network members' behavior, such as their adoption rate, can influence adoption choices (Hogset and Barrett, 2010). Empirical studies have often conflated information diffusion and social influence, and only recently have some empirical studies attempted to disentangle them, as discussed in more detail below.

In this section, we derive a conceptual framework to explain how social networks can affect the adoption of renewable technology by relying primarily on the studies that have attempted to separate the effects of information diffusion and social influence. For example, Banerjee et al. (2013) propose a theoretical framework to model the diffusion of a new product (microfinance loans), with the following implications. First, they assume that, given the same share of adopters, a larger network size, that is a larger number of network members, captures a pure social learning effect by increasing the probability of information being passed on. Second, they model a pure endorsement effect as the effect of the share of adopters, given the same likelihood of receiving information. They then use a randomized control trial and a set of simulations to quantify the two effects and find no evidence of endorsement effects.

\footnotetext{
${ }^{5}$ Social networks have been shown to affect various economic behaviors and outcomes such as job search (Wahba and Zenou, 2005), school performance (Calvó-Armengol et al., 2009), political participation (McClurg, 2003), farm management (Di Falco and Bulte, 2013), and the spread of disease (Eubank et al., 2004).
} 
Similarly, we propose to relate renewable energy technology adoption to both the size of the network to capture information diffusion, and the share of adopters in the network to capture social influence. One particular characteristic of our study design is that it allows to distinguish between learning and non-learning networks in a social network. A learning network is a network comprising members who are informed about the technology. A non-learning network is a network comprising people with whom an individual discusses important matters without this involving any information about the technology. In contrast to studies that use more general measures of social networks (e.g., friends in Cai et al., 2015; friends or neighbors in Liverpool-Tasie et al., 2012), our learning networks are more likely to include key informed network members. In addition, as opposed to studies that focus only on network members that have adopted the technology (e.g., Bandiera and Rasul, 2006), in our study, a social network also includes non-adopters. While Banerjee et al. (2013) find that adopters are more likely to pass on information, they also find that informed non-adopters play an essential role in transmitting information, although they have often been excluded by other measures of learning networks.

Maertens (2017) provides an alternative approach to disentangle the effects of information diffusion and social influence using observational data. In particular, the author is able to exploit information on an individual's beliefs and shows that once beliefs are taken into account, network effects signal strategic behavior in the form of either strategic delay or social pressure inhibiting the adoption of genetically modified cotton. These two mechanisms are separated by comparing the effect of learning and non-learning networks since negative strategic delay should be associated only with the former.

In our setting, we expect social networks to exercise a positive influence on the adoption of biogas. The socio-economic benefits are significant and explain the strong support from the government to the adoption of biogas (Zuzhang, 2013). Hence, the government's involvement and the public good nature of some of the benefits of biogas adoption are likely to have a positive social influence effect on the adoption of biogas. We also expect social influence to be at work outside an individual's biogas-specific learning network. We test this hypothesis by using data on an individual's non-learning network. ${ }^{6}$

Most empirical studies have focused on agriculture-related technologies in developing countries. To the best of our knowledge, no study has yet analyzed social network effects in the context of renewable energy technology. For instance, Foster and Rosenzweig (1995) and Munshi (2004) focus on the adoption of high-yielding seed varieties during India's Green Revolution. Conley and Udry $(2001 ; 2010)$ study farmers learning about pineapple and the adoption of fertilizers in Ghana. Bandiera and Rasul (2006) look at the adoption of a new crop

\footnotetext{
${ }^{6}$ Another study that aims to disentangle the two mechanism is Cai et al. (2015). They consider network effects in the context of weather insurance decisions. Using a randomized experiment, they provide evidence of knowledge diffusion by estimating the direct effects of learning networks (i.e., the number of friends who are informed about insurance) on the individual's understanding of insurance benefits. They are then able to exclude a social influence mechanism by exploiting randomized default options, and comparing the effect of friends' choices with those of other villagers.
} 
variety (sunflowers) in Mozambique. Maertens (2017) considers a new cotton variety in India, while Beaman et al. (2018) investigate the adoption of soil management practices by maize farmers in Malawi. Agricultural technologies often involve trial and error and hence tend to involve a high degree of uncertainty and risk. This explains why the relationship between network size and agricultural adoption has sometimes been found to follow an inverse-U shape, i.e., larger networks encourage households to delay adoption and free-ride on the experience of others (e.g., Bandiera and Rasul, 2006). In the case of biogas, the technology involves a lower level of risk. While there are some reports of complaints about the lack of maintenance and trouble-shooting support, biogas digesters in China are still eligible for government subsidies even if they run far below their full potential or are abandoned shortly after installation (Zuzhang, 2013), which significantly reduces the financial risk incurred by adopters. Hence, in our context, we do not expect strategic delays to play a major role.

Another important factor for the adoption of new technology is its visibility. While some changes in crop variety are highly visible, such as those considered in Liverpool-Tasie et al. (2012), other practices, like the use of organic fertilizer, are more challenging to detect. While information diffusion does not depend on visibility, Hogset and Barrett (2010) argue that social influence is stronger when adoption is easy to observe. This could partially explain why endorsement effects are sometimes not observed in the case of agricultural technology (Banerjee et al., 2013). Given the high visibility of biogas technology, in our study we expect to find both information diffusion and social influence at work.

\section{Data description}

In March and April 2012, we conducted an anonymous survey in twelve rural villages of the Hubei Province of China. ${ }^{7}$ With the help of village leaders, we randomly chose households in each village and invited one decision-maker in each household to carry out the study. For the purpose of our analysis, adopters are defined as those households that have applied or are planning to apply to the biogas subsidy program but have not yet built a biogas pool. We excluded households that have already installed a biogas pool since the application and installation process can take several years and can itself change a farmer's social network and behavior. More importantly, the number and types of people a farmer knows now may not reflect the people they knew when they applied to the program. The final sample comprises 332 observations, with 195 adopters and 137 non-adopters. ${ }^{8}$

Table 1 summarizes the individual and household characteristics of our final sample. On average, respondents are 47 years old and have a middle school education, corresponding to nine years. Most respondents are male (77\%), and more than half worked off-farm. Most households are smallholders with an average plot of land of 0.66 hectares. The average

\footnotetext{
${ }^{7}$ We also conducted two pre-tests to ensure the understanding and quality of our survey. The villages for the pre-tests were excluded from the final sample to avoid contamination.

${ }^{8}$ We exclude 27 households because of missing data on social networks and six households because of missing data on socio-demographic characteristics.
} 
household comprises four people with an annual household income of about $¥ 24,000$. ${ }^{9}$ Adopters are significantly better educated than non-adopters. They also have a higher household income and more animals, whose dung is the primary material for biogas, and are more open to experience. On the other hand, there are no significant differences in age, household size, plot size, and risk propensity.

We identify a respondent's biogas learning network by asking the following question "Who gave you information about the biogas program?" As we explained to respondents in the survey, the term information refers to any information related to the biogas subsidy program and biogas technology, such as how the biogas program is implemented, what biogas is, what it can be used for, what they need to do to use biogas, or what are the benefits of the technology. Burt (1984) suggests that people usually list less than eight people. In the survey, we set the maximum number of people to ten, and no respondent named more than seven. In our data, the size of the learning network measured by the number of people in the biogas learning network varies from one to seven, with a mean value of 2.13 and a standard deviation of 1.09 , as shown in Table 1. The average network size of adopters (2.29) is significantly larger than that of nonadopters (1.91).

\section{[TABLE 1 HERE]}

In addition, we asked respondents whether each person they named had adopted biogas technology. We found considerable variation in the number of known adopters: $13 \%$ of respondents knew no adopters, 38\% knew one adopter, 30\% knew two, and 19\% knew more than two. The average share of known adopters in the learning network is 0.79 . The share of known adopters is significantly larger for adopters than for non-adopters (0.82 versus 0.75$)$.

We also asked respondents about some attributes of each person in their biogas learning network, such as the relationship of each network member to the respondent (family member or relative, friend, neighbor, government official, or other), whether a network member lives inside or outside the village, and whether the respondent trusts the member of his/her network. We define network members as trusted if the respondent is willing to lend them money or would ask them to take care of their house when away. Such detailed data allow us to explore the composition of the learning network.

The biogas program is a government program advertised to farmers by village-level government officials. Our data show that government officials are the primary information providers about biogas (54\%). However, respondents also receive information from family members or relatives $(13 \%)$, friends $(18 \%)$, and people with other relationships such as neighbors (15\%). About $90 \%$ of the network members providing biogas information to respondents live in the same village as the respondent, so setting geographical boundaries to social networks would have excluded about $10 \%$ of a respondent's learning network. Finally,

\footnotetext{
${ }^{9} ¥ 6 \approx \$ 1$ in 2012 .
} 
most network members providing biogas information to the respondent are considered trustworthy (79\%).

We also collected information on a respondent's overall social network by asking the question: "From time to time, most people discuss important matters with others. Looking back over the last year -who are the people with whom you discussed matters important to you?" This is the most common measure of social networks adopted in other studies (e.g., Banerjee et al., 2013; Cai et al., 2015). For 58\% of respondents, the overall social network and the biogas learning network did not overlap, and for $19 \%$ of respondents, the overall social network includes all members in their learning network.

We then define a non-learning network as the network comprising members with whom the respondent discussed important matters but who do not provide any information about biogas. Table 1 shows that the non-learning network is on average significantly smaller than the learning network $(1.43$ versus $2.13 ; p$-value $=0.000)$ and that the share of known adopters in the non-learning network is also smaller than in the learning network ( 0.43 versus $0.79 ; p$-value $=0.000)$. In addition, the average size of the non-learning network is not significantly different for adopters and non-adopters (1.44 versus $1.40 ; p$-value $=0.775)$, while the average share of known adopters in the non-learning network is significantly higher for adopters than nonadopters $(0.51$ versus $0.32 ; p$-value $=0.000)$.

\section{Empirical approach}

Our empirical approach is informative of whether adoption decisions are associated with information diffusion and social influence, and expands upon the approaches previously adopted in the literature, such as Bertrand et al. (2000), Goolsbee and Klenow (2002), and Bandiera and Rasul (2006), among others. In particular, we estimate the following equation:

$$
y_{i}=\beta_{1} n_{i}+\beta_{2} s_{i}+\mathbf{X}_{\mathbf{i}} \boldsymbol{\beta}_{3}+\mathbf{v}_{\mathbf{v}}+\varepsilon_{i}
$$

where $y$ has value one if respondent $i$ applied or was planning to apply to the biogas program and zero otherwise. In line with our conceptual framework, $n_{i}$ represents the size of a respondent's learning network, which is the number of people from whom respondent $i$ received information on biogas, capturing information diffusion, while $s i$ represents the share of known adopters in the learning network, capturing social influence. ${ }^{10} \mathbf{X}_{\mathbf{i}}$ is a vector of individual characteristics such as age, gender, years of schooling, household size, land size, whether respondent $i$ worked off-farm, household income, and the number of animals (oxen, pigs, or sheep). Animal ownership, in particular, is likely to be an important determinant of biogas adoption as animal waste is the main source of feedstock for a biogas digester. Households with little livestock might not have sufficient manure for the biogas digester, which

\footnotetext{
${ }^{10}$ We exclude adopters who are family members of the respondent because they may live in the same house and therefore have the same adoption status.
} 
makes the technology less financially viable since the cost of buying in feedstock would likely offset private benefits (Zuzhang, 2013).

For estimation, we use a linear probability model with standard errors clustered at the village level. Given the small number of clusters (12 villages), we apply the wild cluster bootstrap- $t$ procedure by Cameron et al. (2008). A linear probability model is preferred, even in the presence of a binary dependent variable, as it is considered to provide good estimates of the partial effects for average values of the explanatory variables, and at the same time, the coefficients allow for a straightforward interpretation of the results. ${ }^{11}$ Measurement errors also cause a smaller bias in linear models than in discrete choice models (Wooldridge, 2010; Angrist and Pischke, 2008). Heteroscedasticity is an underlying feature of linear probability models and is corrected by using clustered standard errors. Nevertheless, we also show conditional (fixed effects) logit estimates in Table A1 of the Appendix, which confirm our linear probability model estimates.

\subsection{Identification strategy}

There are two well-known threats to identification that affect observational studies of network effects (Manski, 1993). The first, also known as correlated effects, relates to the fact that respondents and their network members might behave similarly, hence make similar adoption choices, because they live in the same environment, unobserved by the researcher. We address this concern by including a vector of village-level fixed effects $\left(\mathbf{v}_{\mathrm{v}}\right)$ to control for common unobservable characteristics within localities. Village-level fixed effects capture common factors at the village level that can affect information diffusion and/or lead to correlated adoption choices, such as village institutions, the presence of village notice boards, proximity to markets, or the cohesiveness of the community, among others. This also implies that our empirical strategy exploits variations between individuals within the same village.

A second concern emerges when individual or household characteristics influence network formation and adoption choices. ${ }^{12}$ Individuals have the tendency to link to others with similar characteristics (homophily). These characteristics might also influence adoption. In this study, we can control for a rich set of possible confounders at the individual and household levels. For instance, we collected and included in our full specification information on risk preferences, which could affect technology adoption and network formation but might not be captured by other observable characteristics (Qu et al., 2013; Aklin et al., 2018). Risk preferences are measured by asking individuals, "In general, how would you rate your willingness to take risks? ( 1 = very unwilling; 2 = unwilling; $3=$ neutral; 4 = willing; $5=$ very willing)." Dohmen et al. (2011) show the behavioral validity of this measure as the best predictor of risk propensity in different domains. Individuals who answered "very unwilling to

\footnotetext{
${ }^{11}$ Concerns about predicted probabilities being negative or greater than 100 percent are also limited in our context as, considering our main specification, only $6 \%$ of the observations have a predicted probability that lies outside the $0-100$ range.

12 This is also known as exogenous effects (Manski, 1993).
} 
take risk" or "unwilling to take risk" are classified as risk averse; individuals who answered "neutral" are classified as risk neutral, and individuals who answered "willing to take risk" or "very willing to take risk" are classified as risk loving. We also control for information on the consumption of traditional energy sources such as firewood and straw, coal and liquefied petroleum gas, and variables measuring personality traits that were found to influence the adoption of biogas in a previous related study (He and Veronesi, 2017). Costa and McCrae (1992) classify major personality traits in five domains (i.e., the Big Five): (i) openness to experience, (ii) conscientiousness, (iii) extraversion, (iv) agreeableness, and (v) neuroticism. Our study includes a vector of variables representing these personality traits. See $\mathrm{He}$ and Veronesi (2017) for details on the construction of these variables. Finally, a set of alternative specifications, several robustness checks, and the inclusion of a falsification test and a placebo test presented below confirm the robustness of our results.

\section{Results}

In this section, we begin by presenting the baseline results obtained by estimating equation (1), which represents the relationship between information diffusion and social influence and biogas technology adoption. We then characterize information diffusion and social influence effects by analyzing the composition of the social network. We show that our baseline results are robust to several sensitivity checks and alternative specifications, including a falsification test and a placebo test. We also show that our results are confirmed when accounting for the small number of clusters.

\subsection{Baseline results}

The results of the linear probability model (LPM) are presented in Table 2, where information diffusion and social influence effects are measured, respectively, by the size of the learning network and the share of known adopters. Conditional (fixed effect) logit estimates are shown in Table A1 in the Appendix and confirm our LPM estimates. Square brackets are used for $p$ values obtained by the wild cluster bootstrap-t procedure as described by Cameron et al. (2008) to account for the small number of clusters.

\section{[TABLE 2 HERE]}

We find significant evidence that both information diffusion and social influence are correlated with biogas adoption, as shown in column 1, Table 2 . We show the robustness of our results by progressively including control variables in columns 2-6 (respective coefficients are shown in Table A2 in the Appendix). We begin by adding in column 2 socio-demographic characteristics such as age, gender, years of schooling, household size, land size, number of animals (oxen, pigs, or sheep), off-farm job, and household income, potentially affecting both network and adoption choices. For example, richer households could have the financial 
resources to adopt biogas and also enjoy a larger network because of their status. We observe that male and better-educated respondents are more likely to adopt biogas (Table A2). ${ }^{13}$ Household income is also positively and significantly correlated with adoption. In column 3 , we also control for traditional energy sources such as the consumption of firewood and straw, coal and liquefied petroleum gas, and in column 4 for measures of the Big Five personality traits, i.e., openness to experience, conscientiousness, extraversion, agreeableness, and neuroticism. Using a similar sample, He and Veronesi (2017) show that personality traits, in particular openness to experience, can be a significant determinant of biogas adoption. We confirm the significant correlation between openness and adoption, while our two coefficients of interest remain almost unchanged. Column 5 controls for risk preferences by including risk averse and risk neutral dummy variables. As shown in Table A2 in the Appendix, risk preferences are not significantly correlated with biogas adoption. This is in line with the expectations set out in our conceptual framework (Section 3) that biogas technology is a relatively low-risk technology. This partly explains why we do not find evidence of strategic delays. If strategic delay considerations were in place, the larger the network, the lower the propensity to adopt the technology. Instead, in our case, network size is not negatively correlated with adoption. ${ }^{14}$ Finally, column 6 adds village fixed effects to account for differences between villages and unobservable village characteristics that could affect biogas adoption and the formation of social networks, such as village institutions and distance to markets, among others. Once we include village fixed effects, the coefficient of information diffusion is almost halved, yet it remains positive and statistically significant.

To give a sense of the magnitude of our findings, the full specification in column 6 of Table 2 indicates that a one standard deviation increase in learning network size (0.88) is associated with an increase in the probability of biogas adoption by about 0.04 percentage points from an average adoption of about $59 \%$, which corresponds to about a $7 \%$ increase. Similarly, a one standard deviation increase in the share of known adopters $(0.35)$ is associated with a 0.07 percentage point increase in the probability of adoption, which is about a $12 \%$ increase with respect to the average adoption rate.

\subsection{Robustness checks}

Results obtained so far suggest the presence of an information diffusion effect since respondents with a larger learning network are more likely to apply for biogas even when controlling for possible confounders at the village and individual levels. The underlying mechanism supporting this finding is that network members convey relevant information about biogas technology that can either increase awareness or reduce learning costs and hence increase adoption. We can provide support for this mechanism by performing a falsification

\footnotetext{
${ }^{13}$ Kelebe et al. (2017) investigate the determinants of biogas adoption in Ethiopia and find that education is positively correlated with biogas adoption as in our study. However, they find that in Ethiopia female headed households are more likely to adopt biogas compared to men headed households.

${ }^{14}$ This is also confirmed when the square term of network size is included as in Bandiera and Rasul (2006). We do not find evidence of an inverse-U shape relationship.
} 
test that exploits the respondent's wider network and a placebo test that uses information on alternative renewable energy technologies.

In particular, we begin by considering a respondent's non-learning network, which represents the network members with whom the respondent discusses important matters but not biogas. This implies that there is no overlapping between the learning network and the non-learning network. Table 3 compares the association between these two types of networks and biogas adoption via a falsification test. Because non-learning networks by definition include members that do not provide relevant information about biogas, we expect them not to be correlated with biogas adoption. Results shown in column 1 of Table 3 confirm our expectations and show that the size of the non-learning network is not associated with the decision to adopt biogas. It is important to note that differences in network members' characteristics do not drive this result. Members of the non-learning network are no less trusted than those in the learning network (87\% of members in the non-learning network are trusted versus $79 \%$ of members in the learning network). This is relevant because trust matters for information diffusion, as shown below.

\section{[TABLE 3 HERE]}

In the case of social influence, what matters is aggregate behavior, i.e., the rate of adoption by known people (i.e., the overall network), as argued in Hogset and Barret (2010). In our study, known people are included either in the learning network if they provide information about the biogas technology, or in the non-learning network if they do not. We expect that social influence should be at work irrespective of whether network members provide information on biogas; hence the effect should be visible for both types of network. In line with our expectations, column 1 of Table 3 shows that social influence operates through both types of networks: the share of known adopters in both the learning and non-learning networks is positively correlated with biogas adoption, and the two correlations are not statistically different $(p$-value $=0.615)$.

In addition, to corroborate that our measure of the learning network indeed captures information diffusion and social influence specific to biogas, we perform a placebo test, expecting biogas learning networks not to be correlated with the adoption of other technologies. Our survey includes information on whether a respondent has installed solar panels. The average adoption rate of solar panels is $52 \%$. Results in column 2 of Table 3 confirm that the size of the biogas learning network and the share of known biogas adopters are not correlated with the adoption of solar panels. It is worth noting that about $32 \%$ of the respondents have adopted both solar panels and biogas, hence the two technologies are no substitutes, which might otherwise explain the insignificant results.

An additional concern is that the reported number of known biogas adopters may involve measurement error. We follow Bandiera and Rasoul (2006) and perform their robustness check to mitigate this concern. First, although what matters for social influence to affect adoption is respondents' perception of technology adoption, if there is a measurement error, this should be 
more serious for illiterate respondents. Table A3 in the Appendix shows that our results are confirmed when illiterate respondents ( $1 \%$ of the sample) are dropped.

\subsection{Characterizing information diffusion and social influence}

This section uses the information available on the characteristics of network members to characterize information diffusion and social influence further. We begin by considering the relationship between a respondent and each member of her/his biogas learning network. Column 1 of Table 4 distinguishes between network members who are government officials, hence with a public role, and family members, relatives, or friends. A final category includes other types of relationships, such as neighbors. Column 2 distinguishes between network members trusted by the respondent and those who are not. ${ }^{15}$ Finally, column 3 considers network members who live within or outside a respondent's village.

\section{[TABLE 4 HERE]}

Focusing first on information diffusion, we find that the association between information diffusion and biogas adoption is largely driven by the information provided by family and friends (column 1), trusted network members (column 2), and those living outside the village (column 3). The latter result is suggestive of a proactive search for information, as discussed in Hogset and Barrett (2010). These authors suggest that social learning is a more precise process of information exchange, and information is more effective when it is actively sought, which in our case seems to refer to seeking information outside one's village.

Conversely, the correlation between information from government officials and biogas adoption is insignificant. This can be surprising at first, but not unexpected once additional evidence is taken into account. Government officials are among the best informed about the biogas program, hence we would expect them to play an important role in terms of information diffusion. Yet, information from officials does not seem to translate into adoption. One possible explanation can be found in our second set of results, where we explore the role of trust (column 2). Trust matters. Only information provided by trusted network members is significantly correlated with respondents' biogas adoption. This suggests that lower levels of trust can partly explain the ineffectiveness of information from government officials. Indeed, on average, $77 \%$ of government officials are trusted compared to $93 \%$ of respondents' relatives. Taken together, this suggestive evidence indicates that the "messenger matters as much as the message," and information from public officials is less effective when they enjoy relatively lower levels of trust.

When we focus on the association between social influence and biogas adoption, however, we find that the share of known adopters who are government officials is significantly and positively correlated with adoption (column 1). Column 2 shows that social influence is equally

\footnotetext{
${ }^{15}$ A contact is considered trusted if respondents are willing to lend her/him money, or they would ask her/him to take care of their home during their absence.
} 
exercised by both trusted and not-trusted network members as the two correlations are not statistically different ( $p$-value $=0.12$ ). In addition, what matters for the adoption decision is also the share of known adopters living in the village of the respondent (column 3). Note that while we cannot make causality claims, the results in column 3 , showing that only the share of known adopters within a village matters for the adoption decision, are consistent with social influence. If our results were driven by projection bias, this would also be reflected in the positive correlation between known adopters outside the villages and adoption, which is not the case. This adds confidence to the interpretation of our results as social influence.

As discussed in the conceptual framework, social influence can be the result of endorsement or conflict avoidance behavior where one harmonizes one's own beliefs with prevailing beliefs. These mechanisms are particularly effective where the technology is visible, as in the case of biogas, which requires the installation of an external pool noticeable by fellow villagers. The visibility of choices ensures that adoption can be observed by others, signaling endorsement. Our results provide support for these arguments. Developing biogas infrastructure has been a key objective of the national development program of the government of China, which highlights the broader environmental and health benefits of the technology. Hence, these results can be interpreted as a form of alignment with public authorities and/or fellow villagers in support of a common cause. These findings suggest that government officials are more likely to promote technology adoption by leading by example rather than spreading information.

\section{Conclusions}

This paper provides novel findings on how social networks are associated with renewable technology adoption through information diffusion and social influence, focusing on biogas technology in rural China. We find that social networks can promote the adoption of renewable technology by spreading relevant information and exercising social influence. Empirically, we find that farmers who know a larger number of informed network members are more likely to adopt biogas, irrespective of the share of adopters in their network. Moreover, farmers with a higher share of known adopters among their network members are more likely to adopt biogas, irrespective of the size of their network. The first result differs from Bandiera and Rasul (2006) and Maertens (2017) who find negative network effects due to strategic delays when looking, respectively, at the adoption of a new crop (sunflower) and genetically modified cotton seeds. On the other hand, the second result differs from Banerjee et al. (2013) and Cai et al. (2015) that do not find evidence of social influence when looking, respectively, at microcredit and weather insurance. Our results highlight the importance of considering how the characteristics of the technology interact with network effects.

We also show that information diffusion and social influence are not unconditional. Our findings suggest that the "messenger matters as much as the message" for adopting the technology. In particular, information spreads only through trusted network members, such as friends and family, while government officials mainly exercise social influence. These findings have some important policy implications. Information diffusion through government officials is not the most effective way to encourage adoption. Farmers are more affected by observing 
government officials' adopting the technology rather than merely receiving information from them. Information diffusion through network members with closer relationships such as friends and family has larger correlations. Our findings suggest that government officials are more likely to promote technology adoption by leading by example rather than spreading information.

Although our results are robust to a set of alternative specifications that exploit a rich set of covariates and include a falsification and a placebo test, we cannot completely exclude endogeneity concerns due to additional omitted factors correlated with both information diffusion and social influence and the decision to adopt the technology. Hence, our findings should be interpreted as correlations rather than causal relationships. Nonetheless, given the lack of research documenting the relationship between information diffusion, social influence, and renewable technology adoption, and overall, the role of social networks in affecting this decision, the correlations found in this study can be considered an important initial step towards enhancing our knowledge of the mechanisms affecting the adoption of renewable energy technologies. 


\section{References}

Aklin, M., Bayer, P., Harish, S.P., and Urpelainen, J. (2018). Economics of Household Technology Adoption in Developing Countries: Evidence from Solar Technology Adoption in Rural India. Energy Economics 72: 35-46.

Angrist, J.D. and Pischke, J.S. (2008). Mostly harmless econometrics. Princeton university press.

Bandiera, O. and Rasul, I. (2006). Social Networks and Technology Adoption in Northern Mozambique. The Economic Journal 116: 869-902.

Banerjee, A., Chandrasekha, A.G., Duflo, E. and Jackson, M.O. (2013). The Diffusion of Microfinance. Science 341 (6144): 1236498.

Baranzini, A., Carattini, S., and Péclat, M. (2017). What Drives Social Contagion in the Adoption of Solar Photovoltaic Technology? GRI Working Papers 270, Grantham Research Institute on Climate Change and the Environment.

Beaman, L., Yishay, A.B., Magruder, J. and Mobarak, A.M. (2018). Can Network Theorybased Targeting Increase Technology Adoption? NBER Working Paper 24912.

Bertrand, M., Luttmer, E.F.P. and Mullainathan, S. (2000). Network Effects and Welfare Cultures. Quarterly Journal of Economics 115: 1019-1055.

Bollinger, B. and Gillingham, K. (2012). Peer Effects in the Diffusion of Solar Photovoltaic Panels. Marketing Science, 31(6):900-912.

Bursztyn, L., Ederer, F., Ferman, B. and Yuchtman, N. (2014). Understanding Mechanisms Underlying Peer Effects: Evidence from a Field Experiment on Financial Decisions. Econometrica 82(4): 1273-1301.

Burt, R.S. (1984). Network Items and the General Social Survey. Social Networks 6 (4): 293339.

Cai, J., De Janvry, A. and Sadoulet, E. (2015). Social Networks and the Decision to Insure. American Economic Journal: Applied Economics 7(2): 81-108.

Calvó-Armengol, A., Patacchini, E. and Zenou, Y. (2009). Peer Effects and Social Networks in Education. The Review of Economic Studies 76(4): 1239-1267.

Cameron, A. C., Gelbach, J.B. and Miller, D.L. (2008). Bootstrap-Based Improvements for Inference with Clustered Errors. Review of Economics and Statistics 90(3): 414-427.

Conley, T.G. and Udry, C.R. (2001). Social Learning Through Networks: The Adoption of New Agricultural Technologies in Ghana. American Journal of Agricultural Economics 83(3): 668-673.

Conley, T.G. and Udry, C.R. (2010). Learning about a New Technology: Pineapple in Ghana. The American Economic Review 100 (1): 35-69.

Costa, P.T., McCrae, R.R. (1992). Revised NEO Personality Inventory (NEO-PI-R) and NEO Five-Factor Inventory (NEO-FFI) Professional Manual. Psychological Assessment Resource, Odessa, FL.

CRESP (2008). Research Report on "Promotion and Management of Rural Energy Projects." China renewable energy scale-up programme.

Di Falco, S. and Bulte, E. (2013). The Impact of Kinship Networks on the Adoption of RiskMitigating Strategies in Ethiopia. World Development 43: 100-110. 
Dohmen, T., Falk, A., Huffman, D., Sunde, U., Schupp, J. and Wagner, G.G. 2011. Individual Risk Attitudes: Measurement, Determinants, and Behavioural Consequences. Journal of the European Economic Association 9: 522-550.

Eubank, S., Guclu, H., Kumar, V.A., Marathe, M.V., Srinivasan, A., Toroczkai, Z. and Wang, N. (2004). Modelling Disease Outbreaks in Realistic Urban Social Networks. Nature 429(6988): 180-184.

Foster, A.D. and Rosenzweig, M.R. (1995). Learning by Doing and Learning from Others: Human Capital and Technical Change in Agriculture. Journal of Political Economy 103(6): 1176-1209.

Foster, A.D. and Rosenzweig, M.R. (2010). Microeconomics of Technology Adoption. Annual Review of Economics 2(1): 395-424.

Goolsbee, A. and Klenow, P.J. (2002). Evidence on Learning and Network Externalities in the Diffusion of Home Computers. Journal of Law and Economics 45: 317-344.

Granovetter, M. (1973). The Strength of Weak Ties. American Journal of Sociology 78(6): 1360-1380.

Graziano, M. and Gillingham, K. (2015). Spatial Patterns of Solar Photovoltaic System Adoption: The Influence of Neighbors and the Built Environment. Journal of Economic Geography 15(4): 815-839.

He, P., and Veronesi, M. (2017). Personality Traits and Renewable Energy Technology Adoption: A Policy Case Study from China. Energy Policy 107: 472-479.

Hogset, H. and Barrett, C.B. (2010). Social Learning, Social Influence, and Projection Bias: A Caution on Inferences Based on Proxy Reporting of Peer Behavior. Economic Development and Cultural Change 58(3): 563- 589.

Jackson, M.O. (2008). Social and Economic Networks. Princeton: Princeton University Press.

Jackson, M.O. and Yariv, L. (2005). Diffusion on Social Networks. Economie publique/Public Economics 16: 3-16.

Jackson, M.O. and Yariv, L. (2007). Diffusion of Behavior and Equilibrium Properties in Network Games. The American Economic Review 97(2): 92-98.

Katuwal, H. and Bohara, A.K. (2009). Biogas: A Promising Renewable Technology and Its Impact on Rural Households in Nepal. Renewable and Sustainable Energy Reviews 13(9): 2668-2674.

Kelebe, H.E., Ayimut, K.M., Berhe, G.H., and Hintsa, K. (2017). Determinants for Adoption Decision of Small Scale Biogas Technology by Rural Households in Tigray, Ethiopia. Energy Economics 66: 272-278.

Krekel, C., Rechlitz, J., Rode, J., and Zerrahn, A. (2020). Quantifying the Externalities of Renewable Energy Plants Using Wellbeing Data: The Case of Biogas, IZA discussion paper 13959.

Kremer, M. and Miguel, E. (2007). The Illusion of Sustainability. The Quarterly Journal of Economics 122(3): 1007-1065.

Liverpool-Tasie, L.S.O. and Winter-Nelson, A. (2012). Social Learning and Farm Technology in Ethiopia: Impacts by Technology, Network Type, and Poverty Status. Journal of Development Studies 48(10): 1505-1521. 
Maertens, A. (2017). Who Cares What Others Think (or Do)? Social Learning and Social Pressures in Cotton Farming in India. American Journal of Agricultural Economics 99(4): 988-1007.

Manski, C.F. (1993). Identification of Endogenous Social Effects: The Reflection Problem. The Review of Economic Studies 60(3): 531-542.

McClurg, S.D. (2003). Social Networks and Political Participation: The Role of Social Interaction in Explaining Political Participation. Political Research Quarterly 56(4): 449-464.

MOA (2007). Planning of National Rural Biogas Projects (2006-2010). Science and Technology Education Department of Ministry of Agriculture of the People's Republic of China.

MOA (2014). Report on the Work of the Ministry of Agriculture, Ministry of Agriculture Information Office of the People's Republic of China, (http://www.moa.gov.cn/zwllm/zwdt/201404/t20140403_3839737.htm).

Munshi, K. (2004). Social Learning in a Heterogeneous Population: Technology Diffusion in the Indian Green Revolution. Journal of Development Economics 73(1): 185-213.

National Development and Reform Commission (2017). China's National Rural Biogas Development 13th Five-Year Plan, available at http://www.gov.cn/xinwen/201702/10/5167076/files/797001c427eb47b680c0cd77daad4327.pdf.

Panwar, N.L., Kaushik, S.C. and Kothari, S. (2011). Role of Renewable Energy Sources in Environmental Protection: A Review. Renewable and Sustainable Energy Reviews 15(3): 1513-1524.

Qu, W., Tu, Q., and Bluemling, B. (2013). Which Factors are Effective for Farmers' Biogas use?-Evidence from a Large-scale Survey in China. Energy Policy 63: 26-33.

Rajendran, K, Aslanzadeh, S, and Taherzadeh, M.J. (2012). Household Biogas Digesters-A Review. Energies 5(8): 2911-2942.

Rode, J. and Weber, A. (2016). Does Localized Imitation Drive Technology Adoption? A Case Study on Rooftop Photovoltaic Systems in Germany. Journal of Environmental Economics and Management 78: 38-48.

Rogers, E.M. (1995). Diffusion of Innovations. New York: The Free Press.

Wahba, J. and Zenou, Y. (2005). Density, Social Networks and Job Search Methods: Theory and Application to Egypt. Journal of Development Economics 78(2): 443-473.

Wasserman, S. and Faust, K. (1994). Social Network Analysis: Methods and Applications. Cambridge: Cambridge University Press

Weiland, P. (2010). Biogas Production: Current State and Perspectives. Applied Microbiology and Biotechnology 85(4): 849-860.

Wooldridge, J.M. (2010). Econometric Analysis of Cross Section and Panel Data. MIT press.

Zheng, Y.H., Li, Z.F., Feng, S.F., Lucas, M., Wu, G.L., Li, Y., Li, C.H. and Jiang, G.M. (2010). Biomass Energy Utilization in Rural Areas May Contribute to Alleviating Energy Crisis and Global Warming: A Case Study in a Typical Agro-Village of Shandong, China. Renewable and Sustainable Energy Reviews 14: 3132-3139.

Zuzhang, X. (2013). Domestic Biogas in a Changing China: Can Biogas still Meet the Energy Needs of China's Rural Households? London: International Institute for Environment and Development (IIED). 
TABLE 1 -DESCRIPTIVE STATISTICS

\begin{tabular}{|c|c|c|c|c|c|c|c|}
\hline & \multicolumn{2}{|c|}{ Full sample } & \multicolumn{2}{|c|}{ Adopters } & \multicolumn{2}{|c|}{ Non-adopters } & \multirow[t]{2}{*}{ Difference } \\
\hline & Mean & S.D. & Mean & S.D. & Mean & S.D. & \\
\hline \multicolumn{8}{|l|}{ Dependent variable } \\
\hline Biogas adoption $(1=$ yes, $0=$ no $)$ & 0.587 & 0.493 & 1 & 0 & 0 & 0 & $1 * * *$ \\
\hline \multicolumn{8}{|l|}{ Learning network } \\
\hline Learning network size & 2.133 & 1.088 & 2.292 & 1.219 & 1.905 & 0.821 & $0.387 * * *$ \\
\hline Share of known adopters & 0.789 & 0.355 & 0.817 & 0.325 & 0.749 & 0.392 & $0.068 *$ \\
\hline \multicolumn{8}{|l|}{ Non-learning network } \\
\hline Non-learning network size & 1.425 & 1.262 & 1.441 & 1.316 & 1.401 & 1.185 & 0.040 \\
\hline Share of known adopters & 0.433 & 0.470 & 0.513 & 0.476 & 0.320 & 0.439 & $0.192 * * *$ \\
\hline \multicolumn{8}{|l|}{ Socio-demographic characteristics } \\
\hline Age & 47.500 & 8.898 & 46.985 & 8.142 & 48.234 & 9.860 & -1.249 \\
\hline Male $(1=$ male, $0=$ female $)$ & 0.768 & 0.423 & 0.821 & 0.385 & 0.693 & 0.463 & $0.127 * * *$ \\
\hline Years of schooling & 9.099 & 2.175 & 9.462 & 2.029 & 8.584 & 2.277 & $0.878 * * *$ \\
\hline Household size & 4.497 & 1.350 & 4.564 & 1.284 & 4.401 & 1.437 & 0.163 \\
\hline Land size (hectares) & 0.663 & 0.301 & 0.660 & 0.289 & 0.668 & 0.319 & -0.008 \\
\hline Animals (count) & 4.476 & 30.877 & 6.831 & 40.136 & 1.124 & 1.788 & $5.707 * *$ \\
\hline Off-farm job $(1=$ yes, $0=$ no $)$ & 0.521 & 0.500 & 0.559 & 0.498 & 0.467 & 0.501 & $0.091 *$ \\
\hline Household income (¥1000) & 24.352 & 16.212 & 27.272 & 17.653 & 20.197 & 12.867 & $7.075 * * *$ \\
\hline \multicolumn{8}{|l|}{ Energy sources } \\
\hline Consumed firewood/straw (100 Kg) & 5.483 & 12.337 & 4.922 & 9.836 & 6.281 & 15.210 & -1.359 \\
\hline Consumed coal (100 coal balls) & 2.640 & 5.441 & 2.795 & 5.707 & 2.420 & 5.050 & 0.375 \\
\hline Consumed liquefied petroleum gas (tank) & 4.036 & 2.449 & 4.390 & 2.646 & 3.533 & 2.044 & $0.857 * * *$ \\
\hline \multicolumn{8}{|l|}{ Big Five personality traits } \\
\hline Neuroticism & 0.025 & 0.974 & -0.022 & 0.991 & 0.094 & 0.948 & -0.116 \\
\hline Extraversion & -0.004 & 1.010 & 0.029 & 0.985 & -0.053 & 1.047 & 0.082 \\
\hline Openness & 0.009 & 0.966 & 0.105 & 0.961 & -0.126 & 0.960 & $0.231 * *$ \\
\hline Agreeableness & 0.051 & 0.962 & 0.056 & 0.954 & 0.044 & 0.978 & 0.012 \\
\hline Conscientiousness & 0.046 & 0.978 & 0.068 & 0.985 & 0.015 & 0.971 & 0.053 \\
\hline \multicolumn{8}{|l|}{ Risk preferences } \\
\hline Risk averse $(1=$ yes, $0=$ no $)$ & 0.425 & 0.495 & 0.431 & 0.496 & 0.416 & 0.495 & 0.015 \\
\hline Risk neutral $(1=$ yes, $0=$ no $)$ & 0.262 & 0.440 & 0.236 & 0.426 & 0.299 & 0.460 & -0.063 \\
\hline Number of observations & \multicolumn{2}{|c|}{332} & \multicolumn{2}{|c|}{195} & \multicolumn{2}{|c|}{137} & \\
\hline
\end{tabular}

Notes: $¥ 6 \approx \$ 1$. S.D.: standard deviation. A test of differences in means is set out in the last column and shows significance at $* 0.1, * * 0.05$, and $* * * 0.01$ statistical level. 
TABLE 2-BASELINE ESTIMATES

\begin{tabular}{lcccccc}
\hline Dependent variable: biogas adoption $(1 / 0)$ & $(1)$ & $(2)$ & $(3)$ & $(4)$ & $(5)$ & $(6)$ \\
\hline Learning network size & $0.084^{* *}$ & $0.080^{* * *}$ & $0.076^{* * *}$ & $0.076^{* * *}$ & $0.076^{* * * *}$ & $0.046^{* *}$ \\
& $(0.028)$ & $(0.022)$ & $(0.023)$ & $(0.023)$ & $(0.022)$ & $(0.019)$ \\
& {$[0.051]$} & {$[0.020]$} & {$[0.020]$} & {$[0.013]$} & {$[0.023]$} & {$[0.053]$} \\
Share of known adopters & $0.154^{* *}$ & $0.184^{* * *}$ & $0.179^{* * *}$ & $0.185^{* * *}$ & $0.166^{* *}$ & $0.185^{* *}$ \\
& $(0.059)$ & $(0.054)$ & $(0.050)$ & $(0.051)$ & $(0.057)$ & $(0.064)$ \\
& {$[0.023]$} & {$[0.003]$} & {$[0.000]$} & {$[0.001]$} & {$[0.004]$} & {$[0.003]$} \\
Socio-demographic controls & No & Yes & Yes & Yes & Yes & Yes \\
Energy sources & No & No & Yes & Yes & Yes & Yes \\
Big Five personality traits & No & No & No & Yes & Yes & Yes \\
Risk preferences & No & No & No & No & Yes & Yes \\
Village fixed effects & No & No & No & No & No & Yes \\
Observations & 332 & 332 & 332 & 332 & 332 & 332 \\
\hline Nos
\end{tabular}

Notes: Estimates are from a linear probability model. Column 1 includes the learning network size, which captures information diffusion, and the share of known adopters, which captures social influence. Column 2 adds sociodemographic control variables such as age, gender, years of schooling, household size, land size, number of animals, off-farm job, and household income. Column 3 also controls for energy sources such as consumed firewood and straw, coal, and liquefied petroleum gas. Column 4 also includes the Big Five personality traits, i.e., openness to experience, conscientiousness, extraversion, agreeableness, and neuroticism. Column 5 controls for risk preferences by including risk averse and risk neutral dummy variables. Column 6 adds village fixed effects. Estimates of the additional covariates are shown in Table A2 in the Appendix. Standard errors clustered at the village level are presented in parentheses. $p$-values obtained by wild cluster bootstrap-t procedure as described by Cameron et al. (2008) with 200 replications to account for the small number of clusters are shown in square brackets. ** $0.05 * * *$ 0.01 indicate significance levels. 
TABLE 3-FALSIFICATION AND PLACEBO TESTS

\begin{tabular}{|c|c|c|}
\hline Dependent variable: & $\begin{array}{c}\text { Biogas adoption } \\
(1)\end{array}$ & $\begin{array}{c}\text { Solar panel adoption } \\
(2)\end{array}$ \\
\hline \multicolumn{3}{|l|}{ Learning network: } \\
\hline Network size & $\begin{array}{c}0.056 * * \\
(0.018)\end{array}$ & $\begin{array}{c}0.025 \\
(0.026)\end{array}$ \\
\hline & {$[0.014]$} & {$[0.374]$} \\
\hline Share of known adopters & $\begin{array}{l}0.114 * \\
(0.058) \\
{[0.039]}\end{array}$ & $\begin{array}{c}0.007 \\
(0.088) \\
{[0.951]}\end{array}$ \\
\hline \multicolumn{3}{|l|}{ Non-learning network: } \\
\hline Network size & $\begin{array}{c}-0.018 \\
(0.038) \\
{[0.643]}\end{array}$ & $\begin{array}{c}0.009 \\
(0.025) \\
{[0.719]}\end{array}$ \\
\hline Share of known adopters & $\begin{array}{c}0.168 * * \\
(0.071) \\
{[0.037]}\end{array}$ & $\begin{array}{c}0.049 \\
(0.077) \\
{[0.487]}\end{array}$ \\
\hline Socio-demographic controls & Yes & Yes \\
\hline Energy sources & Yes & Yes \\
\hline Big Five personality traits & Yes & Yes \\
\hline Risk preferences & Yes & Yes \\
\hline Village fixed effects & Yes & Yes \\
\hline Observations & 332 & 332 \\
\hline Average adoption rate & 0.587 & 0.518 \\
\hline
\end{tabular}

Notes: Estimates are from a linear probability model. The learning network includes members who provide information about biogas technology, while the non-learning network includes members with whom a respondent discusses important matters but not matters specific to biogas. The network size captures information diffusion while the share of known adopters captures social influence. In column 1, the dependent variable is biogas adoption. In column 2, the dependent variable is solar panel adoption. Socio-demographic control variables include age, gender, years of schooling, household size, land size, number of animals, off-farm job, and household income. Energy sources include consumed firewood and straw, coal, and liquefied petroleum gas. Big Five personality traits are openness to experience, conscientiousness, extraversion, agreeableness, and neuroticism. Risk measures include dummy variables for risk aversion and risk neutrality. Standard errors clustered at the village level are presented in parentheses. $p$-values obtained by wild cluster bootstrap-t procedure as described by Cameron et al. (2008) with 200 replications to account for the small number of clusters are shown in square brackets. $* 0.1 * * 0.05 * * * 0.01$ indicate significance levels. 
TABLE 4-RESULTS BY TYPE OF NETWORK MEMBER

\begin{tabular}{|c|c|c|c|c|c|}
\hline \multirow[t]{2}{*}{ Dependent variable: } & \multirow{2}{*}{$\begin{array}{c}\text { biogas adoption } \\
(1)\end{array}$} & \multicolumn{2}{|c|}{ biogas adoption } & \multicolumn{2}{|c|}{ biogas adoption } \\
\hline & & $(2$ & & (3) & \\
\hline Learning network size: & & Learning netwo & size: & Learning network size: & \\
\hline Government officials & $\begin{array}{l}-0.005 \\
(0.027) \\
{[0.859]}\end{array}$ & Trusted & $\begin{array}{c}0.060 * * * \\
(0.019) \\
{[0.010]}\end{array}$ & Inside the village & $\begin{array}{c}0.035 \\
(0.021) \\
{[0.177]}\end{array}$ \\
\hline Family & $\begin{array}{c}0.178^{* * * *} \\
(0.049) \\
{[0.004]}\end{array}$ & Not trusted & $\begin{array}{l}-0.050 \\
(0.056) \\
{[0.418]}\end{array}$ & Outside the village & $\begin{array}{c}0.129 * * \\
(0.051) \\
{[0.048]}\end{array}$ \\
\hline Friends & $\begin{array}{l}0.110 * * \\
(0.048) \\
{[0.066]}\end{array}$ & & & & \\
\hline Others & $\begin{array}{l}0.106^{*} \\
(0.057) \\
{[0.067]}\end{array}$ & & & & \\
\hline Share of known adopters: & & Share of known & lopters: & Share of known adopters & \\
\hline Government officials & $\begin{array}{c}0.306^{* * *} \\
(0.086) \\
{[0.007]}\end{array}$ & Trusted & $\begin{array}{c}0.143^{*} \\
(0.067) \\
{[0.080]}\end{array}$ & Inside the village & $\begin{array}{c}0.213 * * * \\
(0.067) \\
{[0.001]}\end{array}$ \\
\hline Family & $\begin{array}{c}0.022 \\
(0.151) \\
{[0.884]}\end{array}$ & Not trusted & $\begin{array}{c}0.237 \\
(0.150) \\
{[0.142]}\end{array}$ & Outside the village & $\begin{array}{c}0.038 \\
(0.156) \\
{[0.836]}\end{array}$ \\
\hline Friends & $\begin{array}{c}0.099 \\
(0.143) \\
{[0.514]}\end{array}$ & & & & \\
\hline Others & $\begin{array}{l}-0.088 \\
(0.096) \\
{[0.485]}\end{array}$ & & & & \\
\hline Socio-demographic controls & Yes & & Yes & & Yes \\
\hline Energy sources & Yes & & Yes & & Yes \\
\hline Big Five personality traits & Yes & & Yes & & Yes \\
\hline Risk preferences & Yes & & Yes & & Yes \\
\hline Village fixed effects & Yes & & Yes & & Yes \\
\hline Observations & 332 & & 332 & & 332 \\
\hline
\end{tabular}

Notes: Estimates are from a linear probability model. The learning network size captures information diffusion while the share of known adopters captures social influence. Column 1 includes network members who are government officials, family members or relatives, friends, and other types of members such as neighbors. Column 2 includes trusted and non-trusted network members. Column 3 includes network members who live in or outside a respondent's village. Socio-demographic control variables include age, gender, years of schooling, household size, land size, number of animals, off-farm job, and household income. Energy sources include consumed firewood and straw, coal, and liquefied petroleum gas. Big Five personality traits are openness to experience, conscientiousness, extraversion, agreeableness, and neuroticism. Risk measures include dummy variables for risk aversion and risk neutrality. Standard errors clustered at the village level are presented in parentheses. $p$-values obtained by wild cluster bootstrap-t procedure as described by Cameron et al. (2008) with 200 replications to account for the small number of clusters are shown in square brackets. $* 0.1 * * 0.05 * * * 0.01$ indicate significance levels. 


\section{Appendix}

\section{TABLE A 1 - CONDITIONAL LOGIT (FIXED EFFECTS) ESTIMATES}

\begin{tabular}{lccc}
\hline Dependent variable: & $\begin{array}{c}\text { Biogas adoption } \\
(1)\end{array}$ & $\begin{array}{c}\text { Biogas adoption } \\
(2)\end{array}$ & $\begin{array}{c}\text { Solar panels adoption } \\
(3)\end{array}$ \\
\hline Learning network: & & & \\
$\quad$ Network size & $0.274^{* *}$ & $0.317^{* * *}$ & 0.142 \\
& $(0.114)$ & $(0.110)$ & $(0.116)$ \\
& {$[0.061]$} & {$[0.025]$} & {$[0.294]$} \\
Share of known adopters & $0.980^{* * *}$ & $0.645^{* *}$ & -0.010 \\
& $(0.360)$ & $(0.294)$ & $(0.461)$ \\
Non-learning network: & {$[0.007]$} & {$[0.023]$} & {$[0.992]$} \\
Network size & & & \\
& & -0.088 & 0.029 \\
& & $(0.208)$ & $(0.132)$ \\
Share of known adopters & & {$[0.680]$} & {$[0.823]$} \\
& & $0.906 * *$ & 0.233 \\
& & $(0.374)$ & $(0.368)$ \\
Socio-demographic controls & Yes & {$[0.017]$} & {$[0.516]$} \\
Energy sources & Yes & Yes & Yes \\
Big Five personality traits & Yes & Yes & Yes \\
Risk preferences & Yes & Yes & Yes \\
Village fixed effects & Yes & Yes & Yes \\
Observations & 332 & 332 & Yes \\
\hline Nes & & 332 \\
\hline
\end{tabular}

Note: Estimates are from a conditional logit model with village fixed effects. Estimates are odd ratios. The learning network includes members who provide information about biogas technology, while the non-learning network includes members with whom the respondent discusses important matters but not matters specific to biogas. The network size captures information diffusion while the share of known adopters captures social influence. In column 1 and column 2 , the dependent variable is biogas adoption. In column 3, the dependent variable is solar panel adoption. Sociodemographic control variables include age, gender, years of schooling, household size, land size, number of animals, off-farm job, and household income. Energy sources include consumed firewood and straw, coal, and liquefied petroleum gas. Big Five personality traits are openness to experience, conscientiousness, extraversion, agreeableness, and neuroticism. Risk measures include dummy variables for risk aversion and risk neutrality. Standard errors clustered at the village level are presented in parentheses. $p$-values obtained by wild cluster bootstrap-t procedure as described by Cameron et al. (2008) with 200 replications to account for the small number of clusters are shown in square brackets. * $0.1 * * 0.05 * * * 0.01$ indicate significance levels. 
TABLE A2-BASELINE ESTIMATES

\begin{tabular}{|c|c|c|c|c|c|c|}
\hline $\begin{array}{l}\text { Dependent variable: } \\
\text { biogas adoption }(1 / 0)\end{array}$ & (1) & (2) & (3) & (4) & (5) & (6) \\
\hline \multirow[t]{3}{*}{ Learning network size } & $0.084 * *$ & $0.080 * * *$ & $0.076^{* * *}$ & $0.076 * * *$ & $0.076 * * *$ & $0.046^{* *}$ \\
\hline & $(0.028)$ & $(0.022)$ & $(0.023)$ & $(0.023)$ & $(0.022)$ & $(0.019)$ \\
\hline & {$[0.051]$} & {$[0.028]$} & {$[0.020]$} & {$[0.013]$} & {$[0.023]$} & {$[0.053]$} \\
\hline \multirow[t]{3}{*}{ Share of known adopters } & $0.154^{* *}$ & $0.184 * * *$ & $0.179 * * *$ & $0.185^{* * *}$ & $0.166^{* *}$ & $0.185^{* *}$ \\
\hline & $(0.059)$ & $(0.054)$ & $(0.050)$ & $(0.051)$ & $(0.057)$ & $(0.064)$ \\
\hline & {$[0.023]$} & {$[0.002]$} & {$[0.000]$} & {$[0.001]$} & {$[0.004]$} & {$[0.003]$} \\
\hline \multirow[t]{3}{*}{ Age } & & -0.003 & -0.003 & -0.004 & -0.004 & -0.004 \\
\hline & & $(0.002)$ & $(0.002)$ & $(0.002)$ & $(0.002)$ & $(0.002)$ \\
\hline & & {$[0.207]$} & {$[0.277]$} & {$[0.132]$} & {$[0.144]$} & {$[0.102]$} \\
\hline \multirow[t]{3}{*}{ Male } & & 0.147 & 0.149 & 0.159 & 0.172 & $0.206^{*}$ \\
\hline & & $(0.097)$ & $(0.100)$ & $(0.103)$ & $(0.101)$ & $(0.104)$ \\
\hline & & {$[0.206]$} & {$[0.191]$} & {$[0.194]$} & {$[0.153]$} & {$[0.079]$} \\
\hline \multirow[t]{3}{*}{ Years of schooling } & & $0.031^{* *}$ & $0.030 *$ & $0.029 *$ & $0.031 * *$ & 0.022 \\
\hline & & $(0.014)$ & $(0.014)$ & $(0.014)$ & $(0.014)$ & $(0.015)$ \\
\hline & & {$[0.067]$} & {$[0.062]$} & [0.089] & {$[0.070]$} & {$[0.185]$} \\
\hline \multirow[t]{3}{*}{ Household size } & & -0.002 & -0.003 & -0.004 & -0.002 & -0.002 \\
\hline & & $(0.020)$ & $(0.021)$ & $(0.022)$ & $(0.021)$ & $(0.026)$ \\
\hline & & {$[0.908]$} & [0.897] & {$[0.871]$} & {$[0.926]$} & {$[0.933]$} \\
\hline \multirow[t]{3}{*}{ Log land size } & & -0.162 & -0.158 & -0.163 & -0.160 & -0.143 \\
\hline & & $(0.169)$ & $(0.155)$ & $(0.145)$ & $(0.148)$ & $(0.141)$ \\
\hline & & {$[0.356]$} & {$[0.354]$} & {$[0.281]$} & {$[0.338]$} & {$[0.351]$} \\
\hline \multirow[t]{3}{*}{ Number of animals } & & 0.001 & 0.001 & 0.000 & 0.000 & 0.000 \\
\hline & & $(0.001)$ & $(0.001)$ & $(0.001)$ & $(0.001)$ & $(0.000)$ \\
\hline & & {$[0.162]$} & {$[0.187]$} & {$[0.458]$} & {$[0.410]$} & {$[0.322]$} \\
\hline \multirow[t]{3}{*}{ Off-farm job } & & 0.021 & 0.024 & 0.024 & 0.020 & 0.042 \\
\hline & & $(0.043)$ & $(0.043)$ & $(0.046)$ & $(0.046)$ & $(0.046)$ \\
\hline & & {$[0.634]$} & {$[0.587]$} & {$[0.612]$} & {$[0.659]$} & {$[0.377]$} \\
\hline \multirow[t]{3}{*}{ Log household income } & & $0.141 * * *$ & $0.131 * * *$ & $0.131 * * *$ & $0.131 * * *$ & $0.119 * * *$ \\
\hline & & $(0.036)$ & $(0.034)$ & $(0.031)$ & $(0.033)$ & $(0.034)$ \\
\hline & & {$[0.004]$} & {$[0.000]$} & {$[0.003]$} & {$[0.002]$} & {$[0.009]$} \\
\hline \multirow[t]{3}{*}{ Firewood/straw } & & & -0.000 & 0.000 & 0.000 & 0.001 \\
\hline & & & $(0.003)$ & $(0.003)$ & $(0.003)$ & $(0.004)$ \\
\hline & & & [0.969] & [0.973] & {$[0.945]$} & {$[0.812]$} \\
\hline
\end{tabular}


TABLE A2-CONTINUED

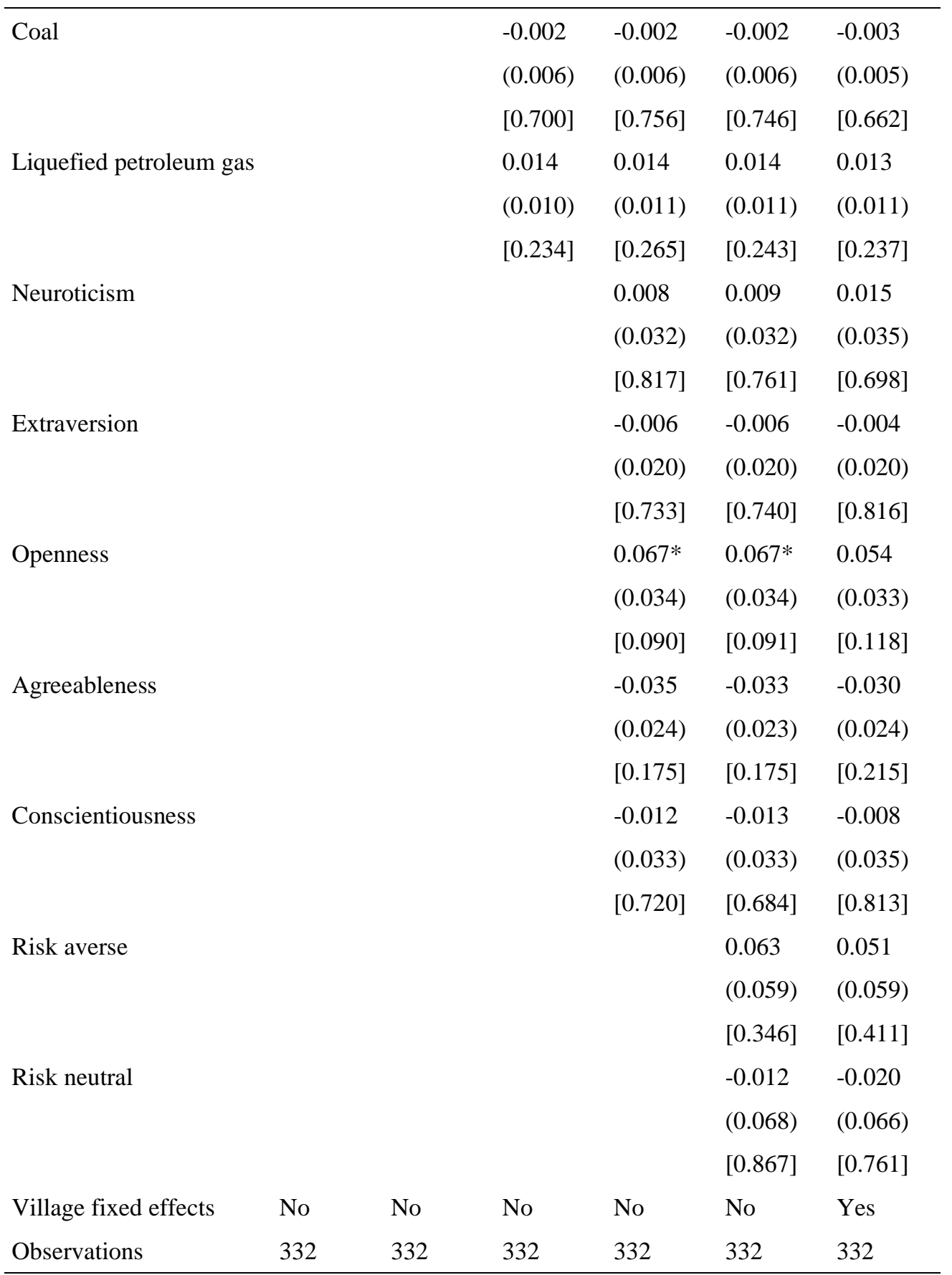

Notes: Estimates are from a linear probability model. Column 1 includes the learning network size, which captures information diffusion, and the share of known adopters, which captures social influence. Column 2 adds socio-demographic control variables such as age, gender, years of schooling, household size, land size, number of animals, off-farm job, and household income. Column 3 also controls for energy sources such as consumed firewood and straw, coal, and liquefied petroleum gas. Column 4 also includes the Big Five personality traits, i.e., openness to experience, conscientiousness, extraversion, agreeableness, and neuroticism. Column 5 controls for risk preferences by including risk averse and risk neutral dummy variables. Column 6 adds village fixed effects. Standard errors clustered at the village level are presented in parentheses. $p$-values obtained by wild cluster bootstrap-t procedure as described by Cameron et al. (2008) with 200 replications to account for the small number of clusters are shown in square brackets. ${ }^{*} 0.05 * * * 0.01$ indicate significance levels. 
TABLE A3-ADDITIONAL ROBUSTNESS CHECK

\begin{tabular}{lc}
\hline Dependent variable: biogas adoption $(1 / 0)$ & \\
\hline Learning network size & $0.045^{* *}$ \\
& $(0.019)$ \\
& {$[0.042]$} \\
Share of known adopters & $0.193^{* *}$ \\
& $(0.062)$ \\
& {$[0.001]$} \\
Socio-demographic controls & Yes \\
Energy sources & Yes \\
Big Five personality traits & Yes \\
Risk preferences & Yes \\
Village fixed effects & Yes \\
Observations & 329 \\
\hline
\end{tabular}

Notes: Estimates are from a linear probability model. Illiterate respondents are excluded. The learning network size captures information diffusion while the share of known adopters captures social influence. Sociodemographic control variables include age, gender, years of schooling, household size, land size, number of animals, off-farm job, and household income. Energy sources include consumed firewood and straw, coal, and liquefied petroleum gas. Big Five personality traits are openness to experience, conscientiousness, extraversion, agreeableness, and neuroticism. Risk measures include dummy variables for risk aversion and risk neutrality. Standard errors clustered at the village level are presented in parentheses. $p$-values obtained by wild cluster bootstrap-t procedure as described by Cameron et al. (2008) with 200 replications to account for the small number of clusters are shown in square brackets. $* * 0.05$ $* * * 0.01$ indicate significance levels. 